\title{
A pregnant Japanese woman returning from Africa with recurrent fevers
}

This article was published in the following Dove Press journal:

International Medical Case Reports Journal

9 December 201 I

Number of times this article has been viewed

\author{
Akihiro Tsukadaira' \\ Tomohiro Sekiguchi' \\ Takashi Ashida ${ }^{2}$ \\ Chinatsu Murashita ${ }^{3}$ \\ Nobuo Itoh ${ }^{3}$ \\ Mikiko Kobayashi ${ }^{4}$ \\ Takashi Kagoshima ${ }^{4}$ \\ Yoshitaka Yamazaki ${ }^{4}$ \\ 'Department of Internal Medicine, \\ ${ }^{2}$ Department of Obstetrics and \\ Gynecology, ${ }^{3}$ Division of Clinical \\ Pathology, lida Municipal Hospital, \\ Yawatacho 438, lida, Japan; \\ ${ }^{4}$ Department of Internal Medicine, \\ Suzaka Prefectural Hospital, Suzaka \\ 1332, Suzaka, Japan
}

Correspondence: Akihiro Tsukadaira Department of Internal Medicine, lida Municipal Hospital,

Yawatacho 438, lida 395-8502,

Japan

Tel $+8 \mid 26521 \quad 1255$

Fax +81265211266

Email 0375@imh.jp

\begin{abstract}
Certain clinical aspects of vivax malaria are no longer defined as benign. We present a case of vivax malaria with three relapses in a pregnant Japanese woman who had returned to Japan from the Comoros Islands in East Africa. Data on the successful delivery, examination of Duffy-blood group antigen, and microscopic findings of growing stages of Plasmodium vivax are thought to be of considerable interest.
\end{abstract}

Keywords: vivax malaria, Duffy-blood group, pregnancy

\section{Introduction}

There is growing evidence that the impact of Plasmodium vivax has been underestimated in developing and poor countries. ${ }^{1,2}$ The difficulty of differential diagnosis and lack of proper treatment of both blood-stage and latent parasites are two of the reasons for the prevalence of vivax malaria.

\section{Case report}

A 28-year-old Japanese woman who had been married to an African man and lived in the Comoros Islands for 1 year was admitted to our hospital in Japan because of chills and severe headache. She was 30 weeks pregnant and had taken medication against malaria 2 months previously when she was in Africa.

Laboratory findings showed leukocyte $(6,600 / \mu \mathrm{L})$ and platelet $\left(6.6 \times 10^{4} / \mu \mathrm{L}\right)$ counts, as well as hemoglobin $(9.7 \mathrm{~g} / \mathrm{dL})$, C-reactive protein (CRP; $19.2 \mathrm{mg} / \mathrm{dL})$, fibrin/fibrinogen degradation products (FDP) $(35.1 \mu \mathrm{g} / \mathrm{mL})$, and FDP D-dimer $(38.5 \mu \mathrm{g} / \mathrm{mL})$ levels. Giemsa staining of peripheral blood using $\mathrm{pH} 7.4$ buffer showed that $1.8 \%$ of the erythrocytes were infected by Plasmodium. After the ring form, schizont, and gametocyte of this parasite were determined (Figure 1), the results of the subsequent rapid diagnostic test and DNA assay led to a diagnosis of vivax malaria.

Seven-day medication (quinine $1500 \mathrm{mg} /$ day) against malaria, administered under strict observation and with the patient's agreement, led to remission. However, vivax malaria relapsed in the 34th week of pregnancy. The presence of latent parasites was suspected to be the cause of the fevers. The next quinine administration resulted in another remission. To exterminate the latent parasites, we assessed mother and child blood glucose-6-phosphate dehydrogenase (G6PD) activities after 39th week spontaneous vaginal delivery, after which she was treated again with primaquine (15 mg/day; 14 days). The new born baby's weight was $2850 \mathrm{~g}$. There were no 


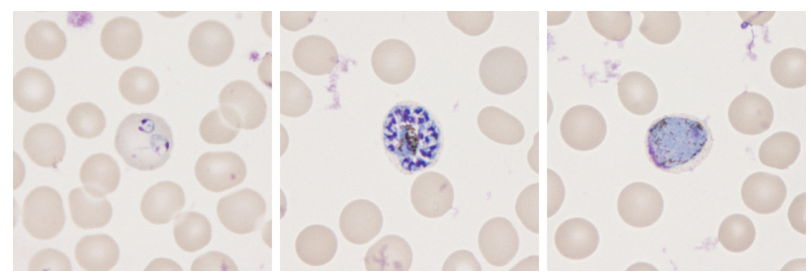

Figure I Microscopic findings of the growing stages of Plasmodium species in erythrocytes, which are known to be the merozoite, trophozoite, schizont, and gametocyte stages. Ring forms of two early trophozoites can be observed in an enlarged erythrocyte (left). The presence of more than 16 merozoites in a mature schizont suggests $P$. vivax infection (center). The presence of a round gametocyte in an enlarged erythrocyte also suggests $P$. vivax infection (right).

Note: Giemsa stainings, original magnification $\times 1000$.

abnormalities in either the baby or the placenta. There was no mother-to-child transmission. Mother and child are healthy after 6 months of anti-relapse therapy.

\section{Discussion}

Four distinct Plasmodium species are known to regularly infect humans: $P$. falciparum, $P$. vivax, $P$. malariae, and $P$. ovale. Certain clinical aspects of vivax malaria are not defined as benign anymore because relapse, severe clinical cases, and drug resistance have been reported for $P$. vivax. ${ }^{1-3}$ Relapse of $P$. vivax and $P$. ovale is known to be triggered by dormant hypnozoites in the liver. ${ }^{2}$

Plasmodium falciparum malaria is defined as malignant and is a major public health problem in Africa, including the Comoros Islands, ${ }^{4}$ while vivax malaria is the major cause of malaria outside Africa, mainly afflicting Asia and the Americas. ${ }^{2}$ Why would vivax malaria be less prevalent in Africa? It is known that Africans with Duffy-blood group antigen negative erythrocytes cannot be infected by $P$. vivax, ${ }^{5}$ because it requires the Duffy-blood group antigen as an obligate receptor for invasion, ${ }^{6}$ and the Duffy-blood group antigen negative phenotype $\mathrm{Fy}(\mathrm{a}-\mathrm{b}-)$ frequently occurs in the native African. ${ }^{7,8}$

On the other hand, treatment of symptomatic vivax malaria during pregnancy is very difficult. It may lead to preterm delivery and fetal loss, and neonates of non-immune mothers may be at a particular risk of congenital malaria resulting from transplacental passage of parasites. ${ }^{9}$ Quinine as well as chloroquine are the drugs of choice for the treatment of vivax malaria. Primaquine, the only therapeutic option for these dormant tissue forms, is contraindicated during pregnancy because of the risk of fetal hemolysis. ${ }^{10}$ Even more noteworthy, low-birth weight associated with vivax malaria has also been reported during second and subsequent pregnancies. ${ }^{11}$
We reported here repeated recurrences of vivax malaria in a Japanese primigravida from the Comoros Islands. Since the Duffy-blood group antigen of our patient was Fy $(a+b-)$, our findings support the notion that we should pay careful attention to the occurrence of $P$. vivax even in Africa, ${ }^{12}$ in addition to the numerous local Duffy-blood group antigennegative populations.

\section{Acknowledgments}

We thank Dr S Kano, Department of Tropical Medicine and Malaria, Research Institute, National Center for Global Health and Medicine in Japan, for evaluating examinations of using the Binax NOW Malaria Rapid Diagnostic Test (Binax Inc, USA) and RT-PCR using QIAGEN - QIAamp DNA Mini Kit for Plasmodium species. We also thank the Japanese Red Cross Society Saitama Blood Center, for their Duffy-blood group antigen evaluations.

\section{Disclosure}

The authors report no conflicts of interest in this work.

\section{References}

1. Price RN, Tjitra E, Guerra CA, et al. Vivax malaria: neglected and not benign. Am J Trop Med Hyg. 2007;77(Suppl 6):79-87.

2. Carlton JM, Adams JH, Silva JC, et al. Comparative genomics of the neglected human malaria parasite Plasmodium vivax. Nature. 2008;455(7214):757-763.

3. Argawal R, Nath A, Gupta G. Noninvasive ventilation in Plasmodium vivax related ALI/ARDS. Intern Med. 2007;46:2007-2011.

4. Rebaudet S, Bogreau H, Silaï R, et al. Genetic structure of Plasmodium falciparum and elimination of malaria, Comoros archipelago. Emerg Infect Dis. 2010;16(11):1686-1694.

5. Chaudhuri A, Polyakova J, Zbrzezna V, et al. Cloning of glycoprotein D cDNA, which encodes the major subunit of the Duffy blood group system and the receptor for the Plasmodium vivax malaria parasite. Proc Natl Acad Sci U S A. 1993;90(22):10793-10797.

6. Michon P, Fraser T, Adams JH. Naturally acquired and vaccine-elicited antibodies block erythrocyte cytoadherence of the Plasmodium vivax Duffy binding protein. Infect Immun. 2000;(6896):3164-3171.

7. Matsuoka H, Hasegawa M, Ishii A, et al. A survey of malaria, glucose6-phosphate dehydrogenase deficiency and Duffy blood group in six localities in Guatemala. J J Trop Med Hyg. 1988;16:1-9.

8. Howes RE, Patil AP, Piel FB, et al. The global distribution of the Duffy blood group. Nat Commun. 2011;2:266.

9. ter Kuile FO, Rogerson SJ. Plasmodium vivax infection during pregnancy: an important problem in need of new solutions. Clin Infect Dis. 2008;46:1382-1384.

10. Baird JK. Neglect of Plasmodium vivax malaria. Trends Parasitol. 2007;23(11):533-539

11. Nosten F, McGready R, Simpson JA, et al. Effects of Plasmodium vivax malaria in pregnancy. Lancet. 1999;354(9178):546-549.

12. Mizuno Y, Kudo K, Kano S. Difficulty of proper diagnosis for an imported vivax malaria patient from Africa. Kansenshogaku Zasshi. 2007;81(5):597-599. Japanese. 
International Medical Case Reports Journal

Dovepress

\section{Publish your work in this journal}

The International Medical Case Reports Journal is an international, peer-reviewed open-access journal publishing original case reports from all medical specialties. Previously unpublished medical posters are also accepted relating to any area of clinical or preclinical science. Submissions should not normally exceed 2,000 words or

4 published pages including figures, diagrams and references. The manuscript management system is completely online and includes a very quick and fair peer-review system, which is all easy to use. Visit $\mathrm{http}: / / \mathrm{www}$.dovepress.com/testimonials.php to read real quotes from published authors.

Submit your manuscript here: http://www.dovepress.com/international-medical-case-reports-journal-journal 